\title{
BIRTHS OF IMAGES AND DEATHS
}

\section{for Stan and Jane Brakhage}

\author{
he turns \\ it is the leather skullcap \\ on his head \\ i am lost \\ they turn through all connections \\ of light \\ in rhythm \\ now they walk behind the smoke \\ and turn \\ they are acting \\ it appears \\ the pit depends on her hair's weight \\ gold into feathers \\ the smoke is them \\ the eyes of doors open \\ it is clay \\ the city on a table \\ the smoke thinks \\ now she is perfectly lit \\ stone is a hummingbird \\ poised feeding at the image \\ and there is more \\ always on the way \\ a simple change like hair's death \\ lips under a nose \\ under eyes teeth \\ behind lips and all in the spectrum of grey
}


where is the lost color?

wandering in the machine

strange boils, scurvy, on the machines

but chosen

the last chord

you must leave now

\section{Tom Raworth}

ONCE OR TWICE

No country would have me

Where I was born slips my mind

Uncontrollably

Once or twice

Climbing unfamiliar steps

I've discovered a lost bend or sock

The host's wife wears

A heavenly smile

In an embroidered frock

So like a good child

I confess my perplexities

Of the two standing at the window

One speaks of his regular habits

In a remote world

Soon he'll hurry

Like a ghost at daybreak

To his rented room

For the first time

You notice me 